\title{
VIDEO SOSIALISASI SUMUR RESAPAN BERBASIS MOTION GRAPHIC PADA HUMAS PEMERINTAHAN KOTA TANGERANG
}

\author{
Lusyani Sunarya ${ }^{1}$ \\ Wahyu Hidayat ${ }^{2}$ \\ Edo Satria Winata ${ }^{3}$ \\ Dosen STMIK Raharja ${ }^{1,2}$,STMIK Raharja Jurusan Teknik Informatika ${ }^{3}$ \\ Jl. Jenderal Sudirman No.40, Modernland, Tangerang ${ }^{1,2,3}$ \\ E-mail: lusyani@raharja.info ${ }^{1}$, wahyu.hidayat@raharja.info ${ }^{2}, \underline{\text { edo@raharja.info }}{ }^{3}$
}

\begin{abstract}
ABSTRAK
Bencana banjir menjadi permasalahan serius di Kota - Kota besar yang ada di Indonesia. Oleh karena itu, banyak Pemerintah daerah mencari solusi untuk mencegah dan mengatasi banjir.Humas Pemerintahan Kota Tangerang merupakan divisi yang bergerak di bidang hubungan masyarakat.Sumur resapan berfungsi memberikan imbuhan air secara buatan dengan cara menginjeksikan air hujan ke dalam tanah. Tujuan penelitian ini, untuk membantu divisi Humas dalam mensosialisasikan tentang manfaat sumur resapan, sebagai solusi untuk mengatasi banjir khususnya di Kota Tangerang.Permasalahannya adalah, media sosialisasi sebelumnya hanya menggunakan media poster, belum ada media dalam bentuk video yang informasinyalengkap dan dikemas secara menarik. Metode penelitian yang digunakan :pengumpulan data, analisa perancangan media, dan konsep produksi media (KPM). Hasil penelitian ini berupa motion graphic2Dyang menjelaskan tentang sumur resapan, proses alur kerja sumur resapan, dan manfaat dari sumur resapan untuk mengatasi banjir. Video ini terdapat unsur gambar, suara, gerak, dan musik yang dibuat dengan software grafis yaitu :Adobe Illustrator CS6, Adobe Premiere CS6, Adobe After Effect CS6, danAdobe Audition CS6. Melalui video sosialisasi sumur resapan ini, akan menjadi edukasi untuk masyarakat Kota Tangerang, dalam menjalankan program pemerintah mengenai cara mengatasi banjir setiap tahunnya dan sebagai sarana informasi yang bermanfaat bagi masyarakat.
\end{abstract}

Kata Kunci : Video Sosialisasi, Informasi, Sumur Resapan

\begin{abstract}
Flood disaster becomes a serious problem in big cities in Indonesia. Therefore, many local governments are looking for solutions to prevent and cope with flooding. Public Relations Tangerang City Government is a division that works in the field of public relations. The absorption well serves to artificially add water by injecting rainwater into the soil. The purpose of this research, to help the public relations division in socializing about the benefits of absorption wells, as a solution to cope with flooding especially in Tangerang City. The problem is, socialization media previously only use media poster, there is no media in the form of video that the information is complete and packaged interestingly. Research method used: data collection, media design analysis, and media production concept. The results of this research are 2D motion graphics that describes absorption wells, wellflow well workflow processes, and the benefits of absorbing wells to cope with flooding. This video contains elements of images, sounds, motion, and music created with graphics software namely: Adobe Illustrator CS6, Adobe Premiere CS6, Adobe After Effect CS6, and Adobe Audition CS6. Through the socialization video of this absorption well, it will be an education for the people of
\end{abstract}


Tangerang City, in running the government program on how to cope with flood every year and as a useful information tool for the community.

Keywords: Socialization Video, Information, Infiltration Well

\section{PENDAHULUAN}

Pada era modernisasi saat ini, sosialisasi dan edukasi sangat berperan penting untuk menjaga kelangsungan hidup yang lebih baik lagi. Dalam mensosialisasikan sebuah video edukasi, membutuhkan media video promosi berupa media audio visual dengan durasi yang singkat namun dapat mempromosikan secara detail sehingga menjadi lebih menarik bagi konsumen $^{[1]}$.Sehingga dapat menjadi sarana efektif dalam menunjang kegiatan sosialisasi.

Saat ini diperlukan kesadaran manusia sedari dini, tindakan nyata, penanggulangan, dan sosialisasi kepada masyarakat umum, untuk menjaga lingkungan sebelum terlambat ${ }^{[2]}$. Dari sarana media yang digunakan untuk mensosialisasikan program adalah dalam bentuk video yang menjadi daya tarik masyarakat untuk melihat dan juga mempraktekan langsung program Sumur Resapan tersebut.

Humas Pemerintahan Kota Tangerang merupakan salah satu divisi yang bergerak di bidang hubungan masyarakat (Public Relation). Sebagai sarana dalam menyampaikan informasi terkini meliputi program kegiatan sumur resapan ini.Bangunan sumur resapan ialah salah satu rekayasa teknik konservasi air berupa bangunan yang dibuat sedemikian rupa sehingga menyerupai bentuk sumur gali dengan kedalaman tertentu yang berfungsi sebagai tempat menampung atau wadah air hujan yang jatuh di atap rumah dan langsung di serap kedalam tanah.

Sumur resapan berfungsi memberikan imbuhan air secara buatan dengan cara menginjeksikan air hujan ke dalam tanah. Sasaran lokasi sumur resapan ini adalah daerah peresapan air di kawasan budidaya, permukiman warga, perkantoran, pertokoan, industri, sarana dan prasarana olahraga serta fasilitas umum lainnya.

Tujuan penelitian ini adalah untuk membantu Humas Pemerintahan Kota Tangerang untuk dapat mensosialisasikan video sumur resapan, agar dapat di pahami dan di terima oleh masyarakat umum.

Permasalahan yang terdapat pada Humas Pemerintahan Kota Tangerang sebelumnya adalah, media yang digunakan dalam kegiatan sosialisasinya hanya menggunakan media poster, belum ada media dalam bentuk video sosialisasi yang menjelaskan secara lengkap mengenai informasi yang dikemas secara menarik. Perancangan video sosialisasi ini, dibutuhkan oleh Pemerintahan Kota Tangerang dalam upaya mensosialisasikan program Pemerintahan Kota Tangerang untuk menyampaikan informasi mengenai Sumur resapan air yang meliputi proses alur kerja sumur resapan dan manfaatnya sumur resapan ini kepada masyarakat luas. Pemerintahan Kota Tangerang belum mempunyai media yang efektif dalam menyampaikan sosialisasi yang informasinya menjelaskan secara detail mengenai program pemerintah yaitu mengenai Sumur resapan air, dalam upaya mengatasi masalah yang ada di Kota Tangerang.

Hasil penelitian ini yaitu berupa perancangan video sosialisasi sumur resapan berbasis motion graphic adalah potongan-potongan media visual berbasis waktu yang menggabungkan film dan desain grafis $^{[3]}$,yang mencakup gambar, suara, dan juga musik yang menjelaskan secara detail mengenai video sosialisasi yang berjudul sumur resapan sebagai pusat informasi 
masyarakat untuk mengatasi banjir. Implementasi dari video sosialisasi ini akan ditunjukan kepada masyarakat Kota Tangerang sebagai target untuk menjalankan program pemerintahan tentang fungsi dari sumur resapan ini. Strategi pemasaran dari video sosialisasi yang dilakukan yaitu : video sosialisasi sumur resapan ini akan tayang pada saat kegiatan Kota Tangerang, Presentasi internal oleh bagian Humas, Penyuluhan ke setiap kecamatan kecamatan yang ada di Kota Tangerang, dan berbagai kegiatan sosialisasi lainnya dalam upaya meningkatkan kesadaran masyarakat akan pentingnya sumur resapan tersebut. Melalui perancangan media video sosialisasi sumur resapan ini akan menjadi edukasi khususnya untuk masyarakat Kota Tangerang, dalam menjalankan program pemerintah mengenai cara mengatasi banjir setiap tahunnya dan sebagai sarana informasi yang bermanfaat bagi masyarakat.

\section{LITERATURE REVIEW}

1. Penelitian yang dilakukan Iskandar $(2017)^{[4]}$ dengan judul "Perancangan Media Sosial Tanggapan Bencana Kabupaten Semarang Berbasis Animasi 2D". Penelitian ini menjelaskan tentang sebuah media sosialisasi tanggap bencana yang disajikan dalam bentuk animasi 2D, yang memuat informasi-informasi terkait tanda-tanda, pencegahan, dan penanggulangan bencana. Media sosialisasi tanggap bencana dalam bentuk video animasi 2D, dapat dijadikan sebagai media yang menarik bagi masyarakat untuk sosialisasi tanggap bencana. Dengan pemilihan grafis, transisi dan ditambah pemberian seorang narator membuat audience tertarik dan untuk menyaksikan media sosialisasi ini.

2. Penelitian yang dilakukan ansadena, dkk (2015) ${ }^{[5]}$ dengan judul "Pengembangan Media Pembelajaran Pola Asuh Kecerdasan Moral Anak Berbasis Video". Penelitian ini merupakan jenis penelitian Research and Development $(R \& D)$ yang menghasilkan sebuah produk video pembelajaran pola asuh kecerdasan moral anak dengan tujuan untuk, 1) menambah minat belajar orang tua khususnya yang tidak mengenyam pendidikan formal tentang pola asuh hingga jenjang perguruan tinggi; 2) menambah pengetahuan tentang pola asuh kecerdasan moral anak usia 4-6 tahun kepada orang tua yang tidak mengenyam pendidikan formal tentang pola asuh hingga jenjang Perguruan Tinggi ; 3) dijadikan informasi dan referensi bagi orang tua, pendidik/penyuluh, mahasiswa dan dosen untuk memanfaatkannya dalam proses pembelajaran agar lebih efektif.

3. Penelitian yang dilakukan Aji, dkk (2015) ${ }^{[6]}$ dengan judul "Media $\boldsymbol{C D}$ Pendidikan Kebencanaan Untuk Masyarakat Dalam Menghadapi Banjir Kali Beringin Semarang". Penelitian tersebut menjelaskan tentang Hasil kognitif masyarakat meningkat setelah menggunakan $C D$ Pendidikan Kebencanaan. Hal ini dapat dilihat dari rata-rata hasil pemahaman kognitif masyarakat yang lebih meningkat setelah menggunakan media CD Pendidikan Kebencanaan dengan sebelumnya. Masyarakat juga memiliki tanggapan posistif yang sangat baik setelah menggunakan CD Pendidikan Kebencanaan.

4. Penelitian yang dilakukan Anita dan Fitria Marisa (2017) ${ }^{[7]}$ dengan judul "Rancangan Video Media Promosi Berbasis Motion Graphic 2D Untuk Meningkatkan Jumlah Mahasiswa Universitas Widyagama Malang". Penelitian ini menerangkan bahwa Penulis memilih media animasi 2D jenis SFA (Short Form Animation) untuk merancang 
media promosi Universitas Widyagama Malang. Dengan SFA diharapkan, dapat menyajikan informasi yang akurat, tepat, dan efektif. Karena jika informasi disajikan terlalu lama, dapat mengurangi minat target promosi. Dengan memanfaatkan kemampuan visual, akan dirancang animasi dengan gambar yang menarik. Agar informasi yang diserap lebih optimal.

5. Penelitian yang dilakukan oleh Mahardhika dan A.F Choiril Anam Fathoni (2013) ${ }^{[8]}$ dengan judul "Storyboard Dalam Pembuatan Motion Graphic". Penelitian tersebut menjelaskan contoh yang digunakan adalah pembuatan iklan menggunakan animasi motion graphic dimana storyboard memiliki peranan penting sebagai blueprint setiap adegan dan memberikan petunjuk untuk melakukan transisi gerakan, layout, blocking, serta mendefinisikan gerakan kamera yang semuanya harus dilakukan berkala dalam produksi animasi. Melakukan perencanaan dahulu sebelum membuat animasi atau motion graphic akan membuat pekerjaan lebih teratur, rapi, dan lebih efisien dalam waktu pengerjaannya.

\section{METODE PENELITIAN}

Berikut beberapa metode peneltian yang dilakukan untuk merancang video sosialisasi Sumur Resapan pada Humas Kota Tangerang, yaitu: (1) Pengumpulan data yang dilakukan dengan cara pengamatan secara langsung (observasi), interviewyang dilakukan dengan Humas Pemerintahan Kota Tangerang dan studi pustaka. (2) Analisa Perancangan media video sosialisasi yang dibutuhkan oleh Humas Pemerintahan Kota Tangerang akan diproduksi dengan software komputer grafis, diantaranya: Adobe Illustrator CS6, Adobe Premiere CS6, Adobe After Effect CS6, dan adobe audition CS6. Dan (3) Konsep Produksi Media (KPM). Perancangan media video sosialisasimelalui beberapa proses perancangan agar mendapat gambaran tentang project yang dibuat. Sehingga memudahkan kita dalam membuat video sosialisasi ini. Tahapan yang dilakukan adalah sebagai berikut:

1. Preproduction

2. Production

3. Post Production

PREPRODUCIION

PRODUCTION

POSTPRODUCIION

Gambar 1. Konsep Produksi Media (KPM) 


\section{HASIL DAN PEMBAHASAN}

\section{Preproduction}

Preproduction merupakan langkah awal suatu project yang dimulai yaitu ide, perencanaan, dan persiapan dari KPM. Ada 7 tahapan di dalam preproduction ini. Proses ini bermula dari ide/gagasan yang disalurkan secara tertata, lalu perancangan sinopsis atau alur cerita, scriptwritting, storyboard, penentuan karakter pemain (talent and crew).langkah terakhir adalah setting alat dan terakhir yaitumembuat time schedule.

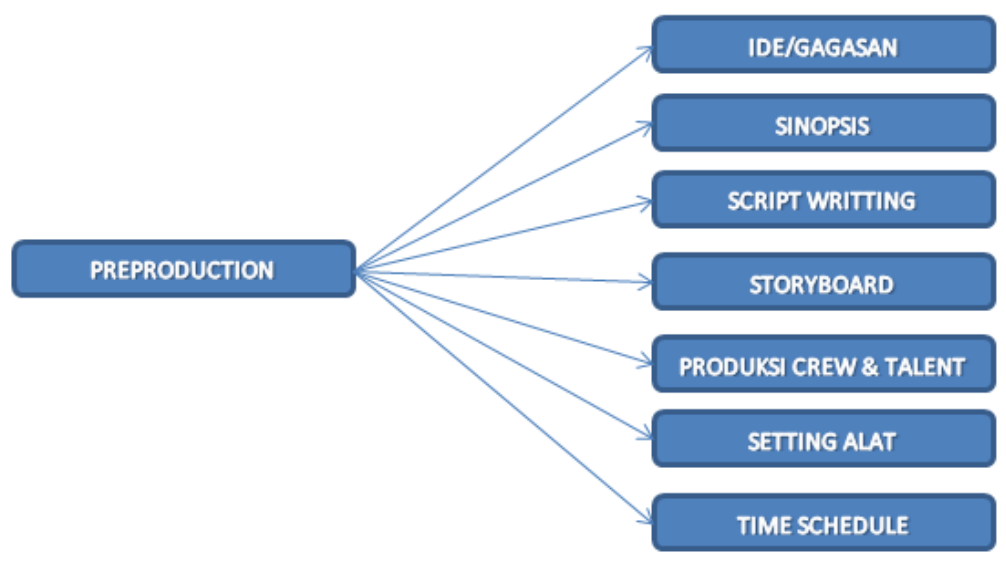

Gambar 2. Preproduction

\section{Ide/Gagasan}

Ide atau gagasan dari pembuatan media video sosialisasi sumur resapan ini, akan dirancang dengan konsep video yang kreatif berbasis motion graphic $2 D$, yang mencakup gambar, suara, dan juga musik yang menjelaskan secara detail mengenai video sosialisasi yang berjudul sumur resapan sebagai pusat informasi masyarakat untuk mengatasi banjir yang di tujukan kepada masyarakat Kota Tangerang.

\section{Sinopsis}

Sinopsis adalah ringkasan sebuah cerita yang akan menjadi gambaran dari semua media pembuatan iklan atau film. Berbentuk pemendekan dari sebuah feature documenter tetapi tetap melihat unsur yang ada di dalam feature documenter tersebut.Dengan adanya sinopsis bertujuan untuk mengetahui secara singkat alur cerita pada sosialisasi penerapansumur resapan bagi warga Kota Tangerang tersebut. Berikut adalah sinopsis dari video sosialisasi ini.

"Pertama-tama akan tampil motion graphic berupa animasi bentuk rumah yang di landa banjir karena tidak ada sumur resapan di sekitarnya. Lalu ada tampilan karakter orang yang menjelaskan sumur resapan, lalu muncul animasi alur air hujan menuju sumur resapan itu dari talang air, jarak sumur resapan minimal 1 meter dari pondasi rumah dan minimal 5 meter dari septic tank, talang pembuangan air hujan, hingga jatuh ke sumur resapan tersebut. Lalu akan 
tampil manfaat dari sumur resapan, dan terakhir muncul logo Kota Tangerang, Tangerang Live, dan Kota Tangerang sebagai support video sosialisasi ini."

\section{Script Writing}

Script Writting adalah sebuah rancangan penulisan naskah secara detail atau rinci yang di dalamnya berupa ide atau gagasan yang sudah kita buat pada sinopsis menjadi sebuah konsep yang menarik.

Script writing dalam video sosialisasi ini seperti berikut:

Tabel 1. Script Writing

\begin{tabular}{|c|c|c|}
\hline NO. & TAKE & KETERANGAN \\
\hline 1 & Take Script 1 & Bumper Opening menampilkan animasi rumah dan hujan deras \\
\hline 2 & Take Script 2 & Menampilkan animasi rumah yang terkena dampak banjir \\
\hline 3 & Take Script 3 & Menampilkan karakter Bang Dane dengan teks yuk kita cegah banjir dengan \\
& & sumur resapan \\
\hline 4 & Take Script 4 & Menampilkan karakter Bang Dane yang menjelaskan tentang sumur resapan \\
\hline 5 & Take Script 5 & Menampilkan animasi proses alur kerja ke sumur resapan \\
\hline 6 & Take Script 6 & Menampilkan karakter Bang Dane dengan teks manfaatnya \\
\hline 7 & Take Script 7 & Menampilkan teks beberapa manfaat dari sumur resapan \\
\hline 8 & Take Script 8 & BumperEnding \\
\hline
\end{tabular}

\section{Storyboard}

Storyboard berisikan rangkaian jalannya cerita atau gambaran yang berupa sketsa gambar dan dilengkapi dengan petunjuk atau cara pengambilan gambar. Yang nantinya akan menjadi acuan selama proses sebelum melakukan shooting. Sehingga kita mempunyai gambaran selama proses produksi.

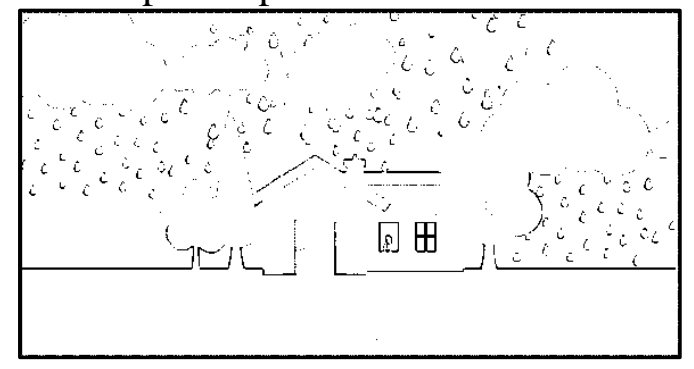

Gambar 3.

Bumper Opening menampilkan Animasi rumah dan hujan deras

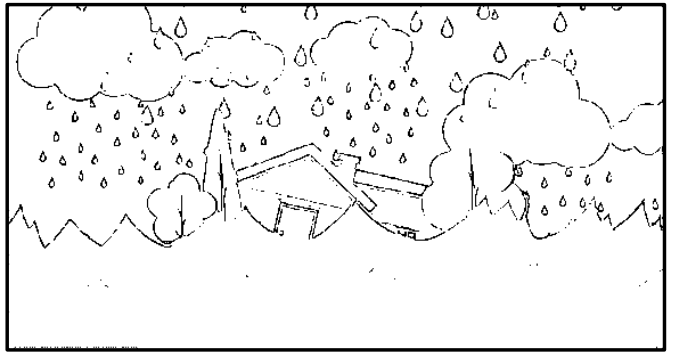

Gambar 4.

Menampilkan animasi rumah yang dampak banjir 


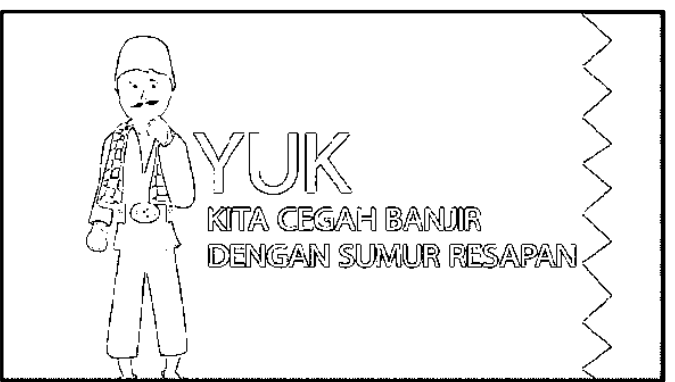

Gambar 5.

Menampilkan karakter Bang Dane dan teks Yuk kita cegah banjir dengan sumur resapan

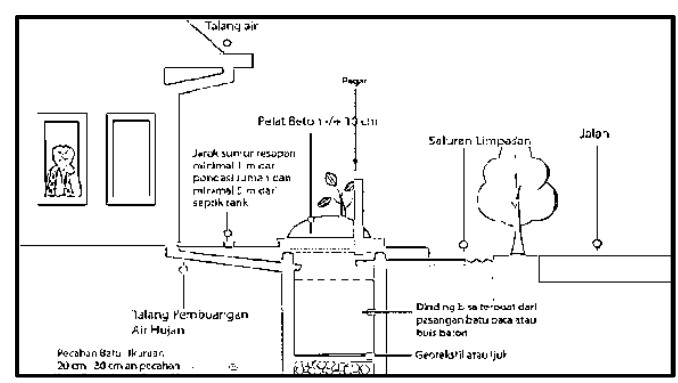

Gambar 7.

Menampilkan animasi proses alur kerja

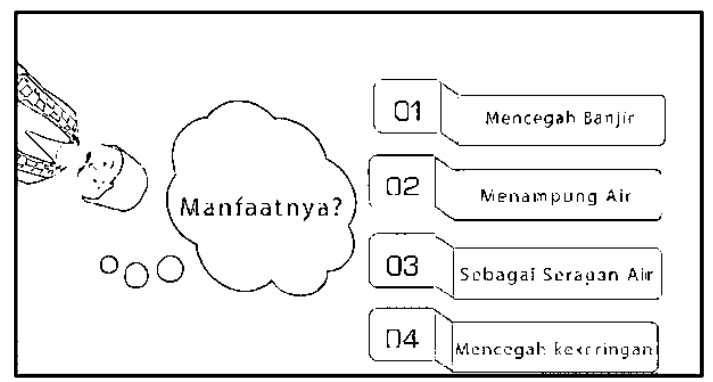

Gambar 9.

Menampilkan teks beberapa manfaat dari Sumur resapan

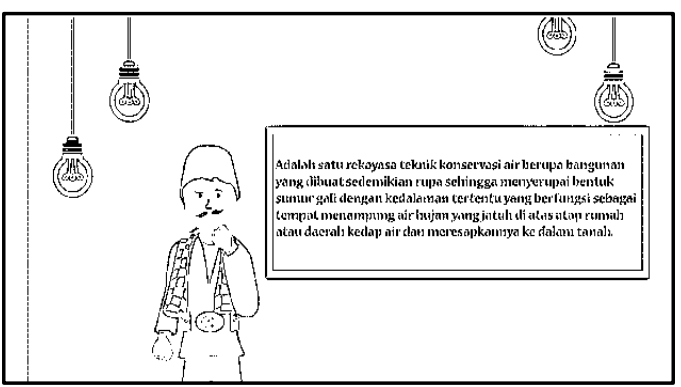

Gambar 6.

Menampilkan karakter Bang Dane yang menjelaskan tentang sumur resapan

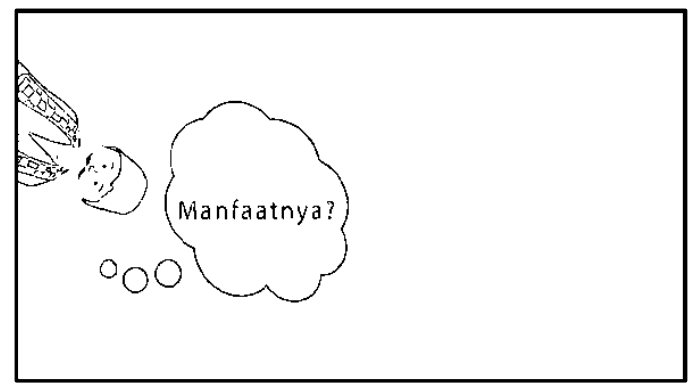

Gambar 8.

Menampilkan karakter Bang Dane sumur resapan dan teks manfaatnya

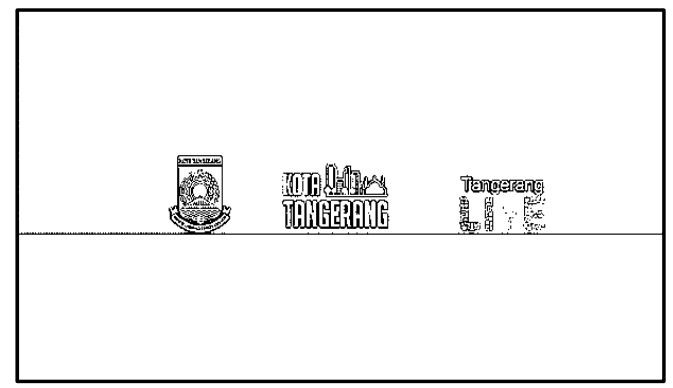

Gambar 10.

Menampilkan bumper ending.

\section{Penyusunan Crew}

Di dalam perancangan video sosialisasi sumur resapan Kota Tangerang Crew sangat di butuhkan untuk pembuatan video sosialisasi ini seperti: sutradara, asisten sutradara, script writting,editor, dan pemeran dari video sosialisasi sumur resapan ini. Di bawah ini merupakan crew dan pemeran yang terlibat dalam pembuatan video sosialisasi sumur resapan pada Humas Pemerintah Kota Tangerang ini, antara lain : 
Tabel 2. Susunan Crew

\begin{tabular}{|c|c|c|}
\hline NO. & JABATAN & NAMA \\
\hline 1 & Sutradara & Lusyani Sunarya \\
\hline 2 & Asisten Sutradara & Wahyu Hidayat \\
\hline 3 & Editor & Edo Satria Winata \\
\hline 4 & Script Writing & Sri Erna Amirullah \\
\hline 5 & Dubber & Dinda Safitri \\
\hline 6 & Pemeran atau Actor & $\begin{array}{c}\text { Karakter Animasi } \\
\text { bernama Bang Dane }\end{array}$ \\
\hline
\end{tabular}

\section{Analisa Perancangan Media}

Dalam perancangan video sosialisasi sumur resapan ini menggunakan softwarekomputer grafis yaitu : Adobe Illustrator CS6,Adobe Premiere CS6, Adobe After Effect CS6, dan adobe audition CS6sebagai pendukung pembuatan motion graphic ini.

\section{Time Schedule}

Tabel3. Time Schedule

\begin{tabular}{|c|c|c|c|c|c|c|c|c|c|c|c|c|c|c|c|c|c|}
\hline \multirow{2}{*}{ Tahapan } & & \multicolumn{4}{|c|}{$\operatorname{Des}(2017)$} & \multicolumn{4}{|c|}{$\operatorname{Jan}(2018)$} & \multicolumn{4}{|c|}{$\mathrm{Feb}(2018)$} & \multicolumn{4}{|c|}{$\operatorname{Mar}(2018)$} \\
\hline & & 1 & 2 & 3 & 4 & 1 & 2 & 3 & 4 & 1 & 2 & 3 & 4 & 1 & 2 & 3 & 4 \\
\hline \multirow{7}{*}{ 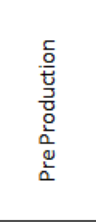 } & Ide & & & & & & & & & & & & & & & & \\
\hline & Time Schedule & & & & & & & & & & & & & & & & \\
\hline & Sinopsis & & & & & & & & & & & & & & & & \\
\hline & Script Writing & & & & & & & & & & & & & & & & \\
\hline & Storyboard & & & & & & & & & & & & & & & & \\
\hline & Pemilihan Talent and Crew & & & & & & & & & & & & & & & & \\
\hline & Setting Alat & & & & & & & & & & & & & & & & \\
\hline \multirow{4}{*}{ 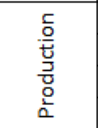 } & Perancangan Multimedia & & & & & & & & & & & & & & & & \\
\hline & \begin{tabular}{|l|} 
Perancangan Audio \\
\end{tabular} & & & & & & & & & & & & & & & & \\
\hline & Perancangan Visual & & & & & & & & & & & & & & & & \\
\hline & Perancangan Broadcasting & & & & & & & & & & & & & & & & \\
\hline \multirow{4}{*}{ 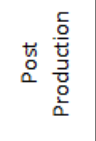 } & & & & & & & & & & & & & & & & & \\
\hline & Capturing, Editing, Mixing, & & & & & & & & & & & & & & & & \\
\hline & dan Finishing & & & & & & & & & & & & & & & & \\
\hline & & & & & & & & & & & & & & & & & \\
\hline
\end{tabular}

\section{Production}

Tahapan Production adalah proses yang sudah memasuki tahap penyusunan dan pengeditan yang menghasilkan sebuah projectvideo. Dimana kerjasama antara talent dan crew sangat diperlukan agar proses produksi berjalan lancar. Production memiliki empat langkah berupa perencanaan multimedia, audio visual, dan perencanaan broadcasting yang berhubungan dengan pengimplementasian video sosialisasi ini. Peran sutradara sangat penting dalam 
tahapan ini untuk mengatur dan menentukan objek karakter yang menjadi daya tarik video sosialisasi ini agar sesuai dengan tahapan yang sudah dibuat sebelumnya.

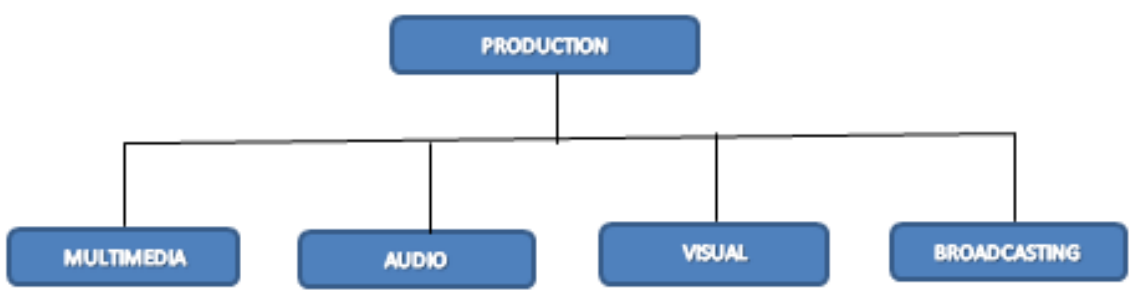

Gambar 11. Production

\section{Post Production}

Post Production merupakan proses akhir diantara proses yang dirancang sebelumnya yaitu preproduction, production, dan post production. proses post production biasa disebut juga sebagai tahap finishing sebuah hasil project sampai menjadi karya yang utuh,dan mampu menyampaikan pesan terhadappenonton. Pada proses ini dilakukan langka editting yang terdiri dari suara, visual, dan flow cerita sesuai sinopsis video sosialisasi yang dirancang pada waktu proses produksi.

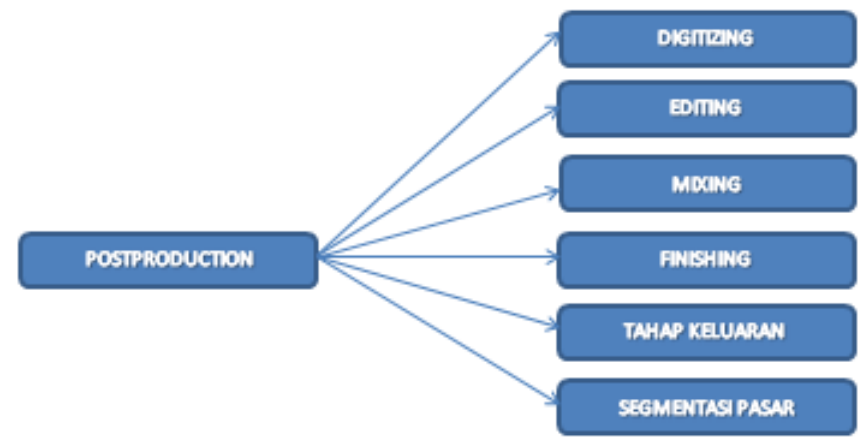

Gambar 12. Postproduction

\section{Tampilan Isi}

Tampilan isi video sosialisasi inimenggambarkan animasi cara mengatasi banjir yang telah dirancang pada saat pembuatan sinopsis. Dan juga meliputi cara kerja sumur resapan. berikut merupakan tampilan isi video sosialisasi yang telah dibuat pada saat proses perancangan Konsep Produksi Media (KPM). 


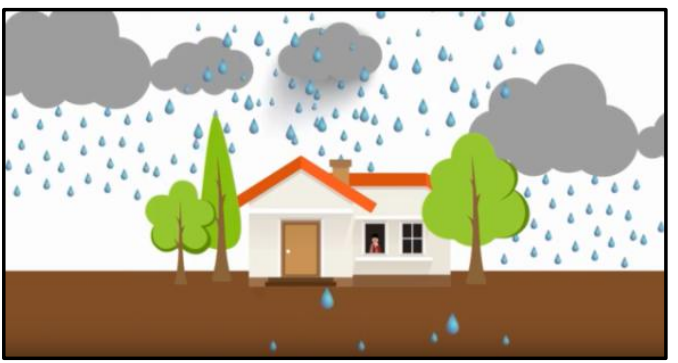

Gambar 13

BumperOpening menampilkan

Animasi rumah dan hujan deras

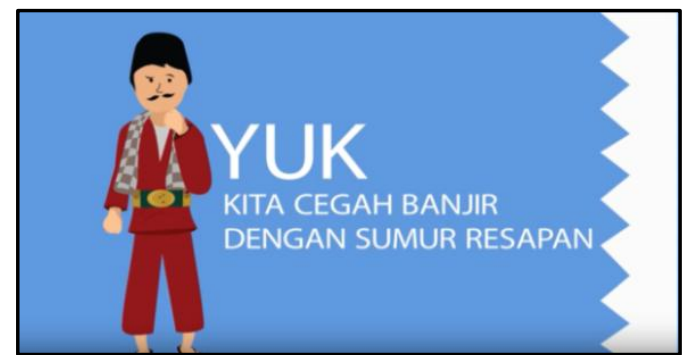

Gambar 15.

BumperOpening menampilkan

Animasi rumah dan hujan deras

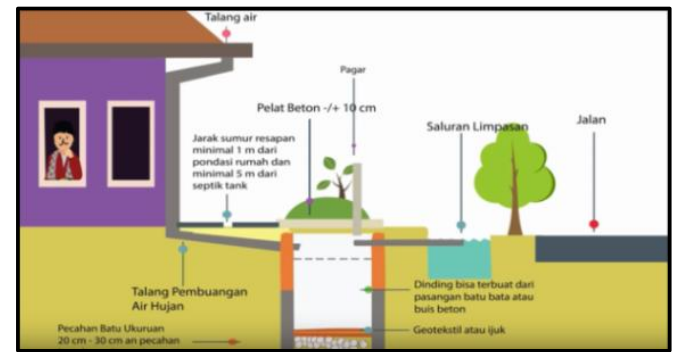

Gambar 17.

Menampilkan animasi proses alur kerja resapan teks manfaatnya

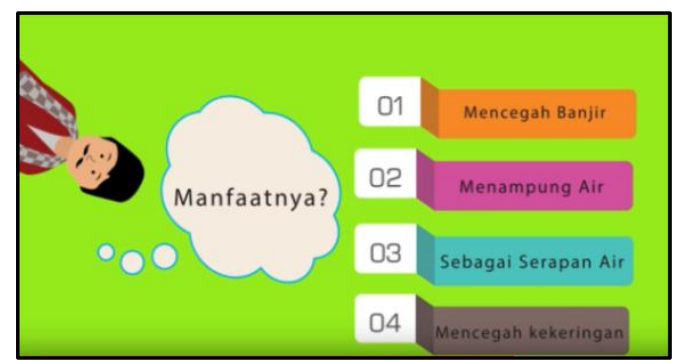

Gambar 19.

Menampilkan teks beberapa manfaat dari Sumur resapan

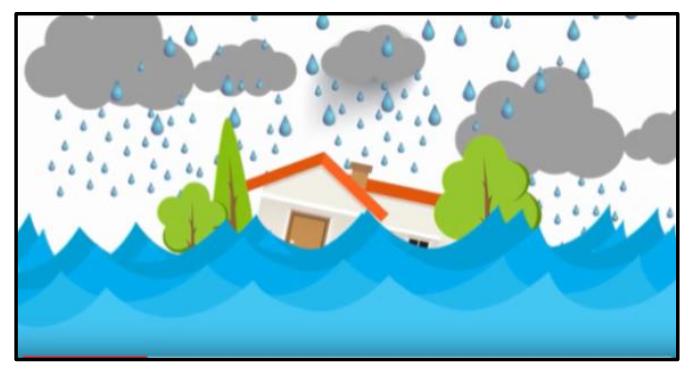

Gambar 14.

Menampilkan animasi rumah yang dampak banjir

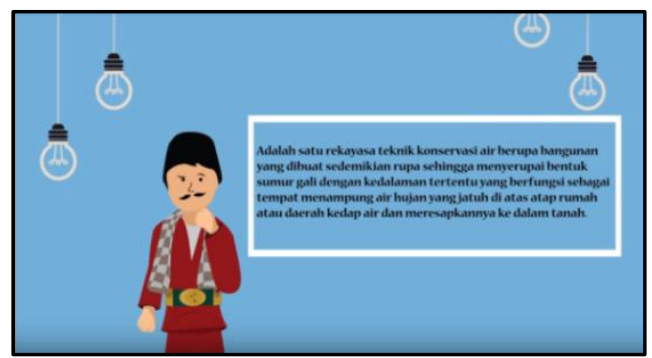

Gambar 16.

Menampilkan animasi rumah yang dampak banjir

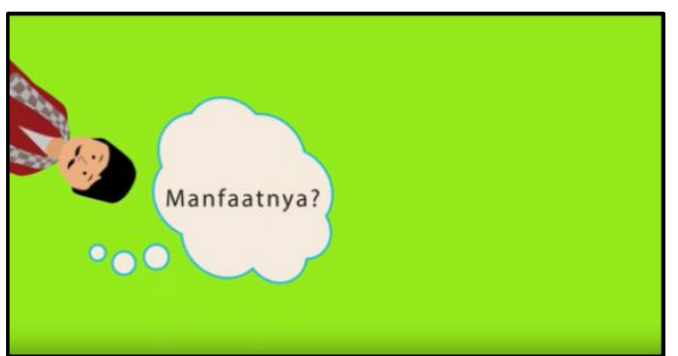

Gambar 18.

Menampilkan karakter bang Dane dengan ke sumur

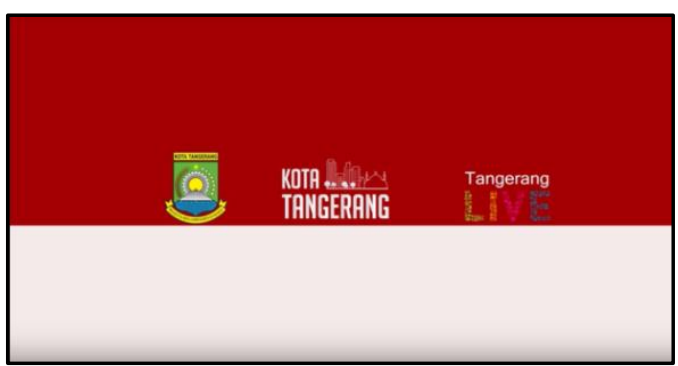

Gambar 20.

Menampilkan bumper ending. 


\section{KESIMPULAN}

Media informasi yang dibutuhkan Divisi Humas pada Pemerintahan Kota Tangerang adalah media video sosialisasi edukasi berbasis Motion Graphic2D, yang mencakup unsur gerak, gambar, suara, dan juga musik yang menjelaskan secara detail mengenai apa yang dimaksud dengan sumur resapan, proses alur kerja sumur resapan, dan manfaat dari sumur resapan untuk mengatasi banjir.Video sosialisasi ini akan ditunjukan kepada Masyarakat luas khususnya warga Kota Tangerang yang belum mengetahui informasi mengenai sumur resapan dan manfaatnya. Melalui perancangan media video sosialisasi sumur resapan yang dikemas menarik dengan teknik animasi 2D ini, akan meningkatkan kesadaran masyarakat Kota Tangerang akan pentingnya sumur resapan untuk mengatasi permasalahan banjir yang sering terjadi di beberapa titik rawan banjir yang ada di Kota Tangerang. Strategi pemasaran dari video sosialisasi yang dilakukan yaitu : video sosialisasi sumur resapan ini akan tayang pada media social seperti youtube, saat kegiatan di Kota Tangerang, Presentasi internal oleh bagian Humas, Penyuluhan ke setiap kecamatan - kecamatan yang ada di Kota Tangerang, dan berbagai kegiatan sosialisasi lainnya, dalam upaya meningkatkan kesadaran masyarakat akan pentingnya sumur resapan tersebut. Melalui perancangan media video sosialisasi sumur resapan ini akan menjadi edukasi khususnya untuk masyarakat Kota Tangerang, dalam menjalankan program pemerintah mengenai cara mengatasi banjir setiap tahunnya dan sebagai sarana informasi yang bermanfaat bagi masyarakat.

\section{SARAN}

Dengan adanya media sosialisasi berupa audio visual ini disarankan agar media tersebut dipergunakan dan diperbarui agar terlaksananya program Pemerintah kepada masyarakat akan pentingnya sumur resapan.Disarankan kepada Pemerintahan Kota Tangerang untuk melakukan program sosialisasi melalui video sosialisasi berbasis Motion Graphic terus dilakukan, sesuai dengan informasi terupdate mengenai Kota Tangerang, serta target sosialisasi ke beberapa daerah yang belum mengetahui program Pemerintahan Kota Tangerang, karena dapat berpengaruh terhadap Perkembangan dan kemajuan Kota Tangerang sendiri.Agar lebih kreatif lagi dalam mensosialisasikan program Pemerintahan Kota dengan menggunakan video promosi berbasis motion graphic $2 \mathrm{D}$, karena masyarakat pada umumnya mudah bosan untuk menyimak sebuah informasi yang kurang menarik. Dan menjadi salah satu pusat edukasi untuk masyarakat terhadap pentingnya menjaga Kota Tangerang.

\section{DAFTAR PUSTAKA}

[1] Permana, Yasa Sidik, 2012, Perancangan dan Pembuatan Video Promosi WisataAlam Dan Edukasi Lingkungan Dolandeso Boro Daerah Banjar AsriKabupaten Kulon Progo, Yogyakarta, STMIK AMIKOM.

[2] Purnasiwi, Mei P Kurniawan, 2013, Perancangan Pembuatan Animasi 2D “Kerusakan Lingkungan” Dengan Teknik Masking, Jurnal Ilmiah DASI, Vol.14 
No.04, Yogyakarta, STIKOM AMIKOM Yogyakarta

[3] Algiffari, Muhammad, 2015, Perancangan Motion Graphic (Bumper In) dan Video Dokumenter Permainan Tradisional Jawa Barat , Jurnal Sketsa, Vol.2 No.1, Bandung, Universitas BSI Bandung

[4] Iskandar, Y.M. Tumimomor, 2017, Perancangan Media Sosialisasi Tanggap Bencana Kabupaten Semarang Berbasis Animasi 2D, Jurnal Ilmu Komputer dan Desain Komunikasi Visual (JIKDISKOMVIS), Vol.2 No.1, Jawa Tengah, Universitas Kristen Satya Wacana

[5] Ansadena, Dewi Tarma, dan Shinta Doriza, 2015, Pengembangan Media Pembelajaran Pola Asuh Kecerdasan Moral Anak Berbasis Video,Jurnal Kesejahteraan Keluarga dan Pendidikan, Vol.4 No.1, Jakarta, Universitas Negeri Jakarta

[6] Aji, Dewi Liesnoor S, Sriyanto, 2015, Media CD Pendidikan Kebencanaan Untuk Masyarakat Dalam Menghadapi Banjir Kali Beringin Semarang, Edu Geography Vol:3 No.5, Semarang, Universitas Negeri Semarang

[7] Anisa, Fitri Marisa, 2017, Rancangan Video Media Promosi Berbasis Motion Graphic 2D Untuk Meningkatkan Jumlah Mahasiswa Universitas Widyagama Malang, Journal of Information Technology and Computer Science (JOINTECS) Vol. 1, No. 2, Malang, Universitas Widyagama Malang

[8] Mahardhika,A.F Choiril Anam Fathoni, 2013, Storyboard Dalam Pembuatan Motion Graphic, HUMANIORA Vol.4 No.2, Jakarta Barat, Binus University 